UDK 781(497.4)

Borut Loparnik

Narodna in univerzitetna knjižnica, Ljubljana

National and University Library, Ljubljana

\title{
Prostor, razmerja in razmere
}

\section{Space, Relations and Circumstances}

Ključne besede: muzikologija, globalnost, nacionalno

POVZETEK

Evropskost in globalnost nista estetsko oz. umetnostno definirana pojma. Še manj sta, če sprejmemo trenutno časnikarsko rabo, nova. Prostor glasbe in zato muzikologije sicer ni zunaj trenutnega ali splošnega, vendar je drugačen, predvsem tesno povezan s historičnim (in nacionalnim). Antihistorizem globalnega "napredka", ki izloča individualno v imenu "dojemljivosti" (uniformnosti po vzoru tržnega povprečja), je torej nasproten vsebini umetniškega. Še zlasti umetnosti "nezgodovinskih" narodov, katerih glasba in ugotovitve o njej že dosihmal niso zanimale "sveta".

Kot nacionalna veda je muzikologija dolžna upoštevati mere vsakokratne družbe in zakonitosti svojega okolja. Vedeti mora, kakšen delež ima v kulturni zavesti naroda sama in kakšnega njen predmet. Gre za vlogo umetniške glasbe, razmerja med praktičnimi glasbeniki in "teoretiki", za znanstveni solipsizem, relevantne teme raziskovanja, za organon in kvaliteto njenega dela. Hkrati mora upoštevati, da se območje neodgovorjenih vprašanj s slehernim pojasnjevanjem preteklega in sočasnega (kajpak tudi evropskega in globalnega) naglo širi. Vezati vse to na skupni imenovalec združevalnih, bolj ko ne futurističnih imaginacij, je sicer oportuni politikum, nikakor pa nazor ali celo orodje znanosti, ki se oblikuje iz umevanja zgodovine. Procesi integracije so zgolj stalna okoliščina umetnostnega dogajanja, ne njegov program. So prvina in ne sinonim glasbenega prostora, razmerij in razmer.
Keywords: musicology, globality, nationality

SUMMARY

Europeanness and globality are neither aesthetically nor artistically defined terms. If we accept current journalistic usage, they are even less new. The place of music, and therefore of musicology, is not outside the momentary or general, but it is different, and above all closely connected with the historical (and the national). Antihistoricism of global "progress", which eliminates the individual in the name of "comprehensiveness" (uniformity following the model of market averages), is thus opposed to artistic contents. All the more so in the art of "unhistorical" nations, the music of which, together with relevant and related observations, have not even hitherto interested "the world".

Musicology, being a discipline of national importance, is obliged to pay regard to the standards of every individual society and to the patterns of its milieu. It has to be aware of its share in the cultural consciousness of the nation as well as of its subject matter. In fact, it is a matter of art music, of relations between "practical" musicians and "theoreticians", of scholarly solipsism, of relevant subjects of research, of its organon and quality of its work. At the same time, musicology has to take into account the fact that the field of unanswered questions is - with each and every explication of the past and present (to be sure, of European and global) - growing rapidly. To reduce all this to a common denominator of unifying or rather futuristic fantasies is quite an opportune political issue, but 
not a scholarly principle, let alone an instrument of scholarship that takes shape through its understanding of history. Processes of integration are only continual circumstances of artistic happenings, not their programme. They are a basic element, and not a synonym of musical space, as well as of musical relations and circumstances.

Naj mi bo dovoljeno, da se oglasim $\mathrm{k}$ besedi brez recentne zagledanosti v modo, ki se ji pravi globalizem. Težko namreč uganem, še teže razberem iz naslova simpozija, čemú se zdi globalnost tako nova in sodobna. Povrhu tudi ugibam, ali bi vsebino pojma zmogli opredeliti do mere, ob kateri bi našel skupno izhodišče vsaj danes zbrani krog. A to sega prek območja napovedane teme. In znane uganke s postmodernizmom oz. tistim, kar hoče ali bi menda hotel veljati, so dovolj opozorila, da je mimobežno razgrebanje na videz umljivih pojmov brez koristi. Najmanj, če že ne celó v primerih, ko jim ponujeni okvir nadeva procese oz. integracije, za katere sta med globalnim in evropskim očitno dopustna bodi enakost bodi nasprotje. Morda upoštevanje vsakršne definicije Evrope alias njenih (temeljnih) značilnosti.

Eno je kljub temu gotovo: svoje nezadostne privrženosti globalizmu ne omenjam iz kljubovanja t.i. trendu, ki nikakor ni bolj spodbuden ali manj brezglav od siceršnjih obrazcev za množično žebranje. Usmerja me zgolj preprosta zgodovinarska (pod)zavest, natančneje njen refleks. Vanj šteje med drugim opozorilo, da Lasso, Haydn ali Dvořák zavoljo svetovljanskih usod niso postali izrazitejši in tudi študije, se pravi sodbe o njih, ne globje ter bolj obvezujoče. Seveda je pri roki ugovor - globalnost (s pomenskimi izpeljankami vred) zadeva občna razmerja, razmere ali vsaj gibanja, šele iz njih vpliva na posameznike in posameznosti. A tudi tu šepeta advocatus diaboli o starih zgodbah. Denimo o množični, na vseh koncih razkričani in razpredeni salonski umetnosti ter tistem, kar je za njo ostalo. Nauk, kot znano, je star: spreminjajo se imena in razsežnosti, bore malo pa namen in pomen dogajanja. Svež primer je že omenjeni, kar moč globalizirani postmodernizem.

Kajpak pod plaščem takih refleksij ne namigujem, da sta prostor oz. vsebina glasbenega - in z njim muzikologije - zunaj sprotnih ali splošnih, tudi docela vsakdanjih uzanc. Zgodovina le uči, da sta drugačna, zato ne pomaga, kadar ju samozadostni antihistorizem odriva pod preprogo globalnosti. Najbrž ju vidi med hudo napotno šaro globalnih (okrajšano pravijo integrativnih) procesov. A kaj so ti nenehoma vzklicevani procesi, kaj integrirajo in kam so namenjeni, je doslej v megli, nemara sploh brez resne teže. Če poslušamo adepte, gre za kratko malo nujno, pravzaprav naravno spremembo, ki uvaja ali vsaj bo utrdila nova razmerja med stvarmi in zanje potrebne okoliščine. Ključna beseda teh kogitacij je seveda metamorfoza ... čeravno je ponavadi mišljen zgolj dobri stari "napredek", torej zgodovinarska utvara o temeljni kategoriji umetniškega dela. Bolj preprosto, brez filozofemskih bergel in siceršje latovščine smemo reči, da nam modni izvedenci ponujajo okorno stesan nadomestek za znan, že dolgo zlorabljan terminus technicus. Povedal naj bi, da je premena vsesplošna, bolje globalna, do nje pa je prišlo $\mathrm{z}$ integracijskim, natančneje prilagoditvenim procesom. 
Videz njegovega novotarstva, absolutne naprednosti, sozvočja s prihodnjim, bistveno moderne(jše)ga habitusa, slutenjske moči itn. vzdržujejo "globalisti" le v zavetju te nepotrebne soznačnice. Podobnih se je (in se jih bo) nateklo še brez števila, večidel od tam, kjer so modne besede ultima ratio, opredelitve lahkotne in smisel napredovanja potrošno blago. Vemo, avantgardno poveličevanje ni bilo izumljeno $\mathrm{v}$ prejšnjem stoletju, četudi je zanj po pravici ostalo signum temporis. Žal tudi ne kaže, da se ga bo tretji milenij odkrižal, kljub marnjam, ki jih venomer meša. In muzikologija ter druge historično kontekstualizirane vede so mu dostopne brez ovir - kadar ne dvomijo o uporabljenem smotru in metodi. Edino z njima se namreč "integracijski proces" razveljavi sam: oznanila še nikoli slišanega/videnega so igra, ki je v zunajzgodovinskem zavetju vendarle vsaj toliko preprosta kot naivna. Konec koncev se dogaja onkraj spoznavnega mišljenja in vseeno je, ali ji primaknejo epiteton globalnosti ali ne.

Vsekakor ni naključje, da spočenja znatno manj sinestetičnih repeticij tista pojmovna plat globalne integracije, ki domala oprijemljivo ironizira do danes uporabljive kalupe t.i. napredka. Mislim kajpak na izvorni smisel "razvojnostne" sintagme, kakor so ga nekritično našli med ekonomsko-politično leksiko ter dodali modni frazeologiji brez nujnih vsebinskih konotacij. V sveti preproščini negira individualno in posebno ter govori zoper edino dosihmal samoumevno zakonitost umetniškega. Prihodnost, je njeno sporočilo, bo(di) čas korenitega, najraje uniformnega poenotenja sub specie globalne dojemljivosti (berimo obvladljivosti). Za mero te nove paradigme se kaže pripravna informacijska naglica, ko bo iz trenutnega opoja dorasla $\mathrm{v}$ zrcalo pravšnosti... In oboje skuša zakriti, morda kje $s$ pristno nedolžnostjo, da je vdano kar moč fiksni, "razumljivi", ob kratkem tržni poprečnosti. Smoter naj bi bil nekaj enakovrednega zabavno-industrijskim uzancam - kalup modne izrabe domišljijskih utrinkov, $\mathrm{v}$ katerem izvirnost pa drugačnost nimata ne temeljne vloge ne selekcijske pravice. Po bistvu nam torej pletejo goli quid pro quo: kar šteje zgodovina med oblikovanje vodil (in "razvoj"), je tu posledica zunajumetnostne načelnosti (in pravilo). Ustvarjanju je dovoljeno varuštvo filozof(em)skih "predvidevanj" oz. "trend" poprejšnje (globalne) analize neizbežnega, ki jo v nazornost prihajajoče dobe modelira množica "pozitivno razmišljujočih". Namesto jasnih aluzij glede vprašanj, s katerimi se ukvarja muzika, bi tu našli bežen opravek kvečjemu splošna psihologija in sociologija.

Mentalni higieni na ljubo torej ne gre pozabiti, da je omenjeno kljub orwellovskim barvam le dobesedna aplikacija globalnega integracionizma, se pravi hrbtna plat rečenice, ki ni bila nikomur vsiljena, ampak zlahka in oberoč sprejeta. Slej ko prej velja za vrhunsko futurološko videnje, komu bolj "naprednih" nemara že za realiteto sodobnosti. S tem kajpak ne trdim, da bi se ne mogla inkarnirati, tudi ne obnavljam Laokoonovih svaril in ne kličem na véliko vojno proti modernemu zlu. Marsikaj napovedovanega bo jutri ali pojutrišnjem dejansko, čeprav drugačno kakor si slika misel. Mnoge menjave bodo zares prilagajale in slednjič enotile razlike v dogajanju, veliko idej, če ne celó dejanj bo kmalu, morda osupljivo zlahka dobilo širok, na videz globalen odmev. Vendar mi zgodovinarski refleks tudi pove, da nisem naštel prida novega. Nov bo kvečjemu hitrejši, prav mogoče površnejši krogotok dogodkov, ampak 
naglica ne zadeva smisla in prostora umetnosti niti med parametri avantgardnega lova na izvirno. Zadeva (in ogroža) ju edino nehistorična pamet, ki bega prek svetov zunaj duhovnega izročila in si prisvaja občutljivo tkivo muzike $\mathrm{z}$ ideološkimi skobami. Nobena globalnost, nikar integracija namreč ne more odtehtati, še manj nadomestiti palimpsesta preteklih vrednot ali vsaj njihove razločnejše, zapisane zgodovine. In natanko tja so položeni odgovori na uganko izvirnega prostora oz. vsebine glasbenega, prav tam velja iskati tudi samosvoje, neredko enkratne poteze njegovih nacionalnih deležev. Ter vede, ki jim sledi.

Po naravi humanističnih znanosti je muzikologija kajpak historična, v dobršni meri celó takrat, ko se loteva sistematike. Vrhu tega je mlada, njeni temelji so razvidno nacionalni, postavljeni $\mathrm{v}$ zavest o pripadnosti in $s$ pripadnostjo večidel omejeni. Kadar jih dandanes hočejo rahljati, v resnici zgolj utišajo ontogenetsko avtarkijo, zato si ne kaže utvarjati globalnosti ali integrativnih potreb. Distinkcije so bolj realne in realistične. Navadno so jih vsilila dovolj dolgo, glasno in na zaležnem kraju izpostavljena (prezrta) dejstva. Kajti narodi so še vedno dveh vrst, "zgodovinski" in "nezgodovinski», z novejšo terminologijo véliki in mali. Eo ipso je sleherno dopolnjevanje znanega težavno, obremenjeno s pomisleki velikih na račun drobnih in malih spričo samodrštva mogočnih. Upati v temeljit preobrat, ki ga obljublja globalnost, je kratko malo vedoma zgrešeno - tega bi se bili lahko naučili že med evropskimi integracijami, denimo od tistih iz habsburških časov naprej.

Njihovi zgledi so nedvoumni: vsako enotenje, združevanje ali povezovanje, ki prihaja "od zunaj", bolj natanko "od zgoraj", brez spontanega, v sebi utemeljenega hotenja oz. potrebe, je obsojeno na votlost. Vsi smo že kdaj doživeli, kako se mu ne dá ogniti, vendar enako nazorno, da sproži upor, podtalnost in pešanje samostojne presoje. Ob kratkem zastoj. Namesto hvalnic apologetov globalnosti bi bila torej pametnejša preudarnost željá - zlasti med "nezgodovinskimi" udeleženci, ki jih niti nove okoliščine ne bodo kmalu pustile $\mathrm{k}$ besedi. Bodimo raje trezni, navsezadnje se jim je enako godilo že dosihmal, brez "globalnih" in kljub "evropskim" procesom. Vsekakor moramo dojeti najmanj dvoje - da so tujini očitno ponujali ugotovitve oz. sodbe, ki je niso (dovolj) zanimale, in/ali da je bila njihova (naša) glasba za svet neprepoznavna. Prvo gre domala v celoti na rovaš muzikologije, drugo se poraja onkraj znanstvenega dosega. Kljub temu je aksiomatično: kot nacionalna veda je muzikologija zavezana nacionalnemu ustvarjanju, naj bodo tuji vplivi in ocene kakršnikoli. Dolžna je iskati relevantne umetniške menjave in dejanja ter najti orodja, ki bodo pojasnila njihovo raven in veljavo. In to ni gola obrtniška naloga, dovoljkrat je predvsem rezultanta razmerij oz. razmer, v katerih se oblikuje kot veda in duhovna intenca. Globalizirajoči procesi so ji kvečjemu sprotni namig za njen okvir, modus, obliko pojasnjevanja, - bolj trendovsko bi se najbrž reklo za trženje dognanj, - nikakor pa organon. Še metodološki napotek samó cum grano salis, kajti opraviti ima z nadvse neglobalno, tudi "integracijsko" docela skromno tvarino. In vsaka tvarina terja ustrezno, se pravi smiselno obravnavo.

Danosti, ki našo vedo spremljajo oz. sodoločajo, je pač treba tehtati z merami družbe in nomosi okolja. Kajpak tvegamo, da bo orisani položaj teže pregleden kakor za varnimi stenami znanstvenega solipsizma, toda razved je slej ko prej konstitutivni parameter življenjskega ozadja in se nanj opira sleherna interpretacija zgodovine. 


\section{MUZIKOLOŠKI ZBORNIK • MUSICOLOGICAL ANNUAL XXXIX}

Prvo in poglavitno je zato vprašanje o deležu muzikologije v kulturni zavesti naroda. Če ga ne razumemo "načelno", bo odgovor bržčas malo spodbuden; konec koncev si je izborilo domovinsko pravico marsikaj vnemarnega že glede t.i. umetniške glasbe. $\mathrm{Na}$ moč sorodne pomisleke bo razbral opazovalec pri določanju mesta, ki ga ima muzikologija med nacionalnimi znanostmi: izvedenska samozaverovanost je postala hujša kot kdaj, meje strok se zdijo nedotakljive. In kdor bo iskal še podrobneje, ga ne smejo zadržati ločnice, ki delijo tudi prostor glasbenega življenja. Med "praktiki" in "teoretiki“, kakor si jih podaja vsakdanja nomenklatura, gospodari vsaj enako globoko nezaupanje, če že ne dosledno nasprotovanje. Med "teoretiki" in ustvarjalci raje in celó kaj bolj izključujočega. Skupni imenovalec teh navzkrižij pa je (večidel do trivialnosti zabrisana) distinkcija, ki pojasnjuje naravi uporabnostne ter znanstvene paradigme, se pravi publicistične in kritiške besede, poročevalskega in raziskovalnega mišljenja. Koliko in kako je takih razmer kriva muzikologija, ali drugače, koliko in kako je njen doslejšnji organon sooblikoval razmerja, ki jo uvrščajo v nacionalni duhovni svet, je seveda apercepcija, ob kateri bi si moral izprašati vest sleherni poklicani, kadar hoče pred javnost. Navsezadnje ga stroka obvezuje, da doume okoliščine in razbere njihovo vlogo pri zorenju dejanj - tudi svojih.

Tako bo pač vedoma uporabil eno tistih (kajpak ne zgolj muzikoloških) vodil, ki bo ostalo nedotaknjeno vsem integracijam navkljub. Imenujmo ga samospraševanje. Še zmeraj se zdi hudo potrebno, nemara je sploh poglavitna zaščita pred vodenênjem občnih in strokovnih meril, ki si na račun globalnih inovacij jemlje "ugled" trendovskih nujnosti. Resnica je namreč, da se dušimo v slabem zadahu banalne pameti in maloumnega postavljaštva. To sicer ni nov ali lokalen blagor integracijskih procesov, gotovo pa memento $z$ ilustracijo, kam (nas) je prignala lahka vera na uzdi preračunljivosti. Konec koncev vemo, vsaj morali bi že uganiti, da drži za uzdo industrijska reklama, iz katere štrli poleg oglaševalskih ideologemov komaj še njega dni sarkastično mišljena parafraza o kvantiteti, ki se levi v nekvaliteto. Jedro je zgolj prodaja (čezmernih količin) tržnega blaga brez umetniške namembnosti. Kar sodi k videzu, skušata o slednji dodati hagiografija "popularnega" ter modrovanje $z$ aplikacijami njenih leksemov - oboje na ravni "preproste" ali "globoke", v izhodišču ter intencah pa enakorodne (zunajglasbene) utilitarnosti.

Gotovo, dokler je šlo za sprotno publicistiko, ni bilo še nič narobe. Težave so se pričele, ko je obseg proizvodnje in recipientov podtaknil "odkritje", da gre za umetniško inovacijo, za "novo(-e) smer(-i)«. Tvarina, ki se (je) ponuja(la), kajpak ni vzdržala strokovne obravnave, še manj takšno preučevanje. Njeno intelektualno zahtevnost in duhovno potenco so mogli opredeljevati le $\mathrm{z}$ besedili, s politično in/ali ideološko konotacijo pétega, sklicevanje na globalnost etc. pa je dobilo vlogo molilnega mlinčka. Toda obstret znanstvenega ni ozaljšal le industrijske glasbene ponudbe, hkrati in dodatno je "utrdil" še krepek del muzikološkega publicizma, ki (je) ribari(l) v enakih vodah. Spregledali so zgolj "drobnarijo" - da zabavljaštvo ne potrebuje "novih" raziskovalnih orodij, ker je množičnost sindrom iz območja socioloških tém, njen povod (glasbena storitev) pa bodi elementaren bodi strojen. In da se muzikologija res ne ukvarja izključno s t.i. visoko umetnostjo, vendar je, bi morala biti, kritična do predmeta svojih raziskav. Kar ji daje pravico na izbor tematike. 
Sliši se kajpak umljivo, toda upoštevati velja, da se območje neodgovorjenih vprašanj s pojasnjevanjem preteklega in sedanjega naglo širi. Prav zato more ob vsakršnih procesih, tudi "evropskih in globalnih", - če in kadar imajo granum salis umetnostnega refleksa, - dobiti koristno spodbudo (teže zgled, raje ne vzorca). V primeru seveda, da bo vedno opravek naše pameti in, upajmo, duha. Kajti za to gre. Brambovsko otepanje s "tujim" je mlatva prazne slame, malikovanje "svetá" rabota novih Ilirjanov: izzivi tičijo v jedru, ki ga poznamo sami. Pri tem so merila za vsebino relevantnih raziskav podvržena stalnim korekturam in so ob nenehno rastoči množici podatkov enako zahtevna kakor odgovorna naloga. Saj ni skrivnost, da opazimo fiziognomijo nacionalne vede najprej $v$ pregledu njenih interesov. Pove nam, kakšen razved ima o gradivu ter nosilnih problemih in kakšna je smer, ki jo hodi.

Če nič drugega, postaja slednja vedno bolj kazalec na tehtnici družbene občutljivosti preučevanja glasbe. Živimo v svetu, ki si vročično želi nove podobe in morda res verjame, da jo bo našel zunaj zgodovine, denimo pri biofatalizmu, kakor naj bi se po kulturologu Ulrichu Raulffu trenutno imenoval rešni nauk. Vendar so, hkrati, v tem istem svetu, bolj in bolj nepregledna žarišča vseh vrst fragmentiranih znanj (tudi glasbeniških), nad katerimi bdijo večidel sprte kohorte specialistov, ki hočejo prvenstvo na ljubo ali pod egido svojih vedenj. Odmev pri občinstvu, socializacija njihovih znanosti ter jezik posredovanja se jim kažejo brez pomena - in natanko enako mislijo na drugem bregu o ceni preteklega ter vlogi historične zavesti. Vezati takšne razmere na skupni imenovalec združevalnih, še raje futurističnih imaginacij, je sicer oportuni politikum, nikakor pa nazor ali celo orodje znanstvenega dela, ki se oblikuje iz umevanja zgodovine.

Kdor raziskuje glasbo, mora tedaj najti pot med bregovoma (današnjega) naprednjaštva, kajpak v primeru, da je zmožen odgovornosti, ki jo terja nacionalna veda. Za takšno usmeritev pa evropski in/ali globalni procesi integracije (pod pogojem, da jih opredelimo) niso program, temveč okoliščina. Gorje mu, kdor jo zanemari, ... toda zgubljen bo tudi, kogar pretenta. Okoliščine so prvina, ne sinonim prostora, razmerij in razmer. 